\title{
Effect of Tongue Stimulation on Upper Extremity Recovery in Stroke Patients - A Randomized Controlled Trial
}

\author{
Jayaprakash Jayavelu ${ }^{1,2}$, Jasobanta Sethi ${ }^{1{ }^{1 *},}$,Sahil kohli ${ }^{2}$, Tariq Matin ${ }^{2}$ \\ ${ }^{1}$ Amity Institute of Physiotherapy, Amity University, Noida, India \\ ${ }^{2}$ Narayana Superspeciality Hospital, Gurugram, India
}

Received September 24, 2021; Revised December 10, 2021; Accepted December 27, 2021

\section{Cite This Paper in the following Citation Styles}

(a): [1] Jayaprakash Jayavelu, Jasobanta Sethi, Sahil kohli, Tariq Matin, "Effect of Tongue Stimulation on Upper Extremity Recovery in Stroke Patients - A Randomized Controlled Trial," Universal Journal of Public Health, Vol. 10, No. 1, pp. 25 - 33, 2022. DOI: 10.13189/ujph.2022.100103.

(b): Jayaprakash Jayavelu, Jasobanta Sethi, Sahil kohli, Tariq Matin (2022). Effect of Tongue Stimulation on Upper Extremity Recovery in Stroke Patients - A Randomized Controlled Trial. Universal Journal of Public Health, 10(1), 25 - 33. DOI: 10.13189/ujph.2022.100103.

Copyright $\subseteq 2022$ by authors, all rights reserved. Authors agree that this article remains permanently open access under the terms of the Creative Commons Attribution License 4.0 International License

\begin{abstract}
Recovery of upper extremity after stroke is always challenging because of various factors. The purpose of this study was to find out the effect of tongue stimulation on upper extremity recovery in stroke patients. Fifty-four stroke patients with informed consent were screened and included in the study after they met the inclusion and exclusion criteria. They were randomly divided into experimental $(\mathrm{N}=26)$ and control group $(\mathrm{N}=28)$ using computerized randomization method followed by comprehensive assessment. Randomization was done by independent assessor. All patients were administered one hour of stroke rehabilitation program in both groups. In experimental group, periglossal electrical stimulation was done for 15 minutes along with upper limb retraining. Patients' functional scores were assessed in both groups at the time of enrolment into the study, which includes modified Rankin Scale and Barthel index, whereas the motor functions were assessed using Fugl-Meyer Assessment Scale. They were reassessed after 4 weeks and 8 weeks of the study. Data analysis was done using SAS software. Test of normality was done to find out the normality of the data. Within group analysis was done using paired $t$ test or Wilcoxin Signed Rank test and between group analysis was done using independent $t$ test or Mann-Whitney U test depending on the normality of the data. Twenty-five stroke patients in control group and twenty-three stroke patients in experimental group completed the study. There was significant improvement in
\end{abstract}

modified Rankin Scale, Barthel index and Fugl-Meyer Scale in both the groups $(\mathrm{P}<0.05)$. Between group analysis revealed that there is significant improvement in modified Rankin Scale, Barthel index, Fugl-Meyer upper extremity and lower extremity scale in experimental group compared to control group $(\mathrm{P}<0.05)$. Tongue stimulation was found to be effective in improving the upper limb functions in stroke patients. This is also cost effective and easy to administer for the benefit of the patients.

Keywords Tongue Stimulation, Upper Extremity Motor Functions, Neuroplasticity, Stroke

\section{Introduction}

Stroke is the second leading cause of morbidity and mortality in the world [1]. Incidence as well as prevalence of stroke has increased in low income and middle-income countries due to rapidly changing lifestyle [1]. Stroke rehabilitation is aimed at reducing the disability and returning the patient to functional status. It involves a team effort by neurologists, physical therapists, occupational therapist, speech therapist, vocational counsellor, psychologist as well as the patient's family members $[2,3]$.

Initial step in rehabilitation is assessment of recovery. Various assessment scales are used to assess the recovery of stroke patients [4]. An ideal assessment scale should be 
simple, reliable, valid, sensitive to changes, should assess all aspects of stroke and can be easily used by the rehabilitation team [4]. One such assessment scale is Fugl-Meyer Assessment Scale for upper extremity and lower extremity, which is a more valid and widely used assessment scale in stroke rehabilitation [3, 4, 5]. Even modified Rankin Scale [6,7] and Barthel functional index [8] are also more valid and reliable scales for evaluating recovery in stroke patients.

Various techniques have been used in the rehabilitation of upper extremity in stroke patients, which include but are not limited to bilateral arm training, biofeedback, brain stimulation using transcranial direct current stimulation, transcranial magnetic stimulation, constraint induced movement therapy, electrical stimulation, hands on therapy, mental practice, mirror therapy, music therapy, repetitive task training, robotics, sensory interventions, strength training, stretching and positioning, task specific training and virtual reality training [9].

Gentilucci et al (2008) stated that speech is accompanied by hand movements and from babbling stage onwards, manual action plays an important role in development of speech. Many studies have proved that Broca's area controls both speech and hand gestures [10]. The movements of tongue for producing vowel sounds and the movements of the hand share the action planning processes [11]. Similarly, movements of the tongue for producing consonants and precision and power grip share the action planning processes $[11,12]$.

Noninvasive electrical stimulation of tongue in addition to balance and mental activity training induces neuroplasticity and improves balance in patients with multiple sclerosis [13]. Tongue stimulation has been used to improve voice quality [14], improve swallowing [15] and improve balance in wide category of patients [16].

Tongue stimulation has been used in rehabilitation of stroke patients for improving balance and motor functions. $[17,18]$. Tongue stimulation along with brain computer interface training has been used to improve upper extremity functions in stroke [17, 18, 19, 20, 21, 22, 23]. However, there is hardly any study done to find out the effect of tongue stimulation along with conventional rehabilitation techniques in improving upper limb functions in stroke patients. Thus, the main objective of this study is to find out the effect of periglossal electrical stimulation on upper limb motor functions in patients with cerebrovascular disease.

\section{Methodology}

\subsection{Subjects}

This was a randomized controlled trial with pre-post experimental design. This was approved by Institutional Ethics Committee of Narayana Superspecialty Hospital, Gurugram, Haryana and Amity University, Uttar Pradesh,
Noida (AUUP/IEC/2018-AUG/06) and registered in clinical trial registry of India (CTRI/2020/03/024353). Stroke patients admitted in Narayana Superspecialty Hospital and / or followed up in outpatient rehabilitation department were screened and explained about the purpose, benefits and methodology of the study. Written informed consent was obtained from patients and for patients whose dominant hand was involved, thumb impression was taken as well as consent taken from spouse or one of the parents. Patients who have suffered first time cerebrovascular accident, both genders, in the age group of 30 to 60 and also in Brunnstorm stage $\geq 2$ were included in the study. Patients were in subacute stage when they were recruited in the study. Patients who were having unstable hemodynamics, uncontrolled arrhythmias, recent myocardial infarction, any musculoskeletal deformity of upper limb before stroke, sensory impairments of tongue, history of seizure and recurrent strokes, and patients who are uncooperative and unable to follow commands were excluded from the study. Recruited patients were randomly divided into experimental group and control group using computerized randomization method (Figure 1).

\subsection{Intervention}

All patients were comprehensively assessed as per institutional protocol and were evaluated using modified Rankin Scale, Barthel functional Index, Fugl-Meyer Assessment Scale for upper extremity and lower extremity. Patients in both the groups underwent one hour of rehabilitation which includes passive stretching, active assisted exercises and functional training using neurodevelopmental approach. It comprises of 10 minutes of bed mobility exercises, 10 minutes of upper limb cycling, 10 minutes of lower limb cycling using Thera-trainer, 15 minutes of upper limb retraining and 15 minutes of balance and gait training. Patients in experimental group were given tongue stimulation along with upper limb training using pen electrode. Assessment and therapeutic procedures were carried out by the principal investigator. Parameters of tongue stimulation include the frequency of $20 \mathrm{~Hz}$, pulse width of 200 microseconds, intensity as minimal threshold experienced by the patient, $3 \mathrm{~mA}$, intermittent stimulation with rest phase; stimulation phase of 10:10. Stimulation was given on periglossal region on three sides - right, left and centre for 15 minutes with oneminute break after every 5 minutes. Electrodes were sterilized with antiseptic solution before and after treating the patient. All patients' tongue were examined after the procedure for any redness, although it is unlikely because of the low intensity of stimulation. All patients and attendants were educated about the home exercise program.

Patients were re-assessed at the end of 4 weeks and 8 weeks of study with respect to modified Rankin Scale, Barthel functional index and Fugl-Meyer Assessment Scale. 
Trial Registration Number: The Trial was registered under Clinical Trial Registration of India CTRI/2020/03/024353.

\subsection{Outcome Measures}

\subsubsection{Primary Outcome Measure}

Fugl-Meyer Assessment Scale (FMA): The Fugl-Meyer Assessment Scale is a more reliable and valid functional assessment scale for stroke patients. It has very high interrater and intra-rater reliability score $(\mathrm{r}=0.98)$ and has a very good criterion and construct validity. Fugl-Meyer scale has got excellent correlation with Barthel index and functional independence measure [5].

Scoring depends on the ability to perform an activity using a 3-point ordinal scale where 2 indicates activity is performed fully, 1 indicates activity is performed partially and 0 is scored when the patient cannot perform an activity. The total score is 226 , out of which motor component score alone is 100 (Upper limb-66, Lower Limb - 34) [14]. FMA motor scores have excellent floor effect and adequate ceiling effect. The minimal clinically important difference of the FMA scores was 12.4 (upper extremity), 5.6 (upper arm), and 4.9 (wrist/hand) [19, 20, 21, 22, 23, 24, 25].

\subsubsection{Secondary Outcome Measures}

Modified Rankin Scale: Modified Rankin Scale is a commonly used scale to assess the degree of disability in stroke patients or other neurological patients. It has very strong construct validity and good test-retest reliability [6, 7]. It is a 7-point ordinal scale where 0 indicates no signs and symptoms of disease, 1 indicates mild signs and symptoms of disease, 2 indicates mild disability, 3 indicates moderate disability, 4 indicates moderately severe disability, 5 indicates severe disability and 6 indicates that the patient is dead. Thus, $0-3$ indicates mild to moderate disability and 4-5 indicates severe disability [26, 27].

Barthel Functional Index: Barthel index is used to assess functional independence of the stroke patients with respect to activities of daily living. It has very good concurrent and construct validity with respect to activities of daily living. Also, Barthel index has very good test-retest reliability. It is a 10 -item scale which includes feeding, bathing, grooming, dressing, bladder and bowel control, toilet dependence, transfer dependence, mobility and ability to negotiate stairs. Scoring ranges between 0 to $100[8,18,19,28]$.

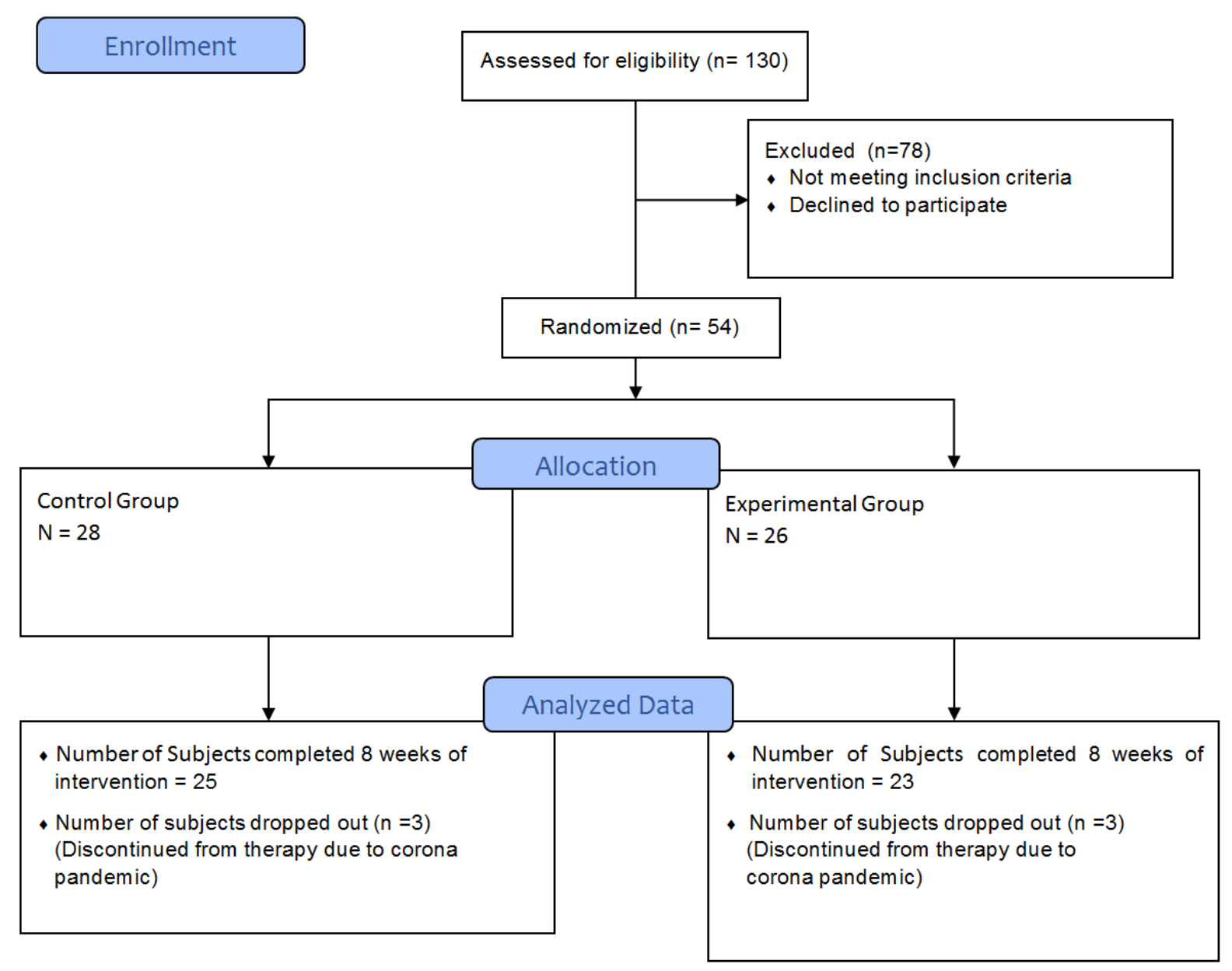

Figure 1. CONSORT Flow Diagram showing recruitment of subjects 


\subsection{Data Analysis}

Data analysis was done using SAS software version 24. Test of normality was done to find out the normality of the data. If the data followed normal distribution, Independent ' $t$ ' test was used to analyse the changes in dependent variables between the groups and paired ' $t$ ' test was used to analyse the data within the group. If the data do not follow normal distribution, then Mann-Whitney $U$ test was to analyse the data between the group and Wilcoxin Signed Rank test was used to analyse the data within the group. Demographic data was presented by means of descriptive statistics. The level of significance was set at $\mathrm{P}<0.05$.

\section{Results}

A total of 54 stroke patients were enrolled for the study. Among them 48 patients completed the study, out of which, 23 patients were in experimental group and 25 patients were in control group. Demographics characteristics of the stroke patients and baseline characteristics of the patients were shown in Table 1 and Table 2. Within group analysis revealed significant changes in modified Rankin Scale, Barthel index, Fugl-Meyer upper extremity motor function and Fugl-Meyer lower extremity motor functions (Graph 1, Graph 2, Graph 3 and Graph 4). Between group analysis also revealed that there are significant changes in modified Rankin Scale, Barthel index, Fugl Meyer Assessment Scale for upper extremity motor function and lower extremity motor function in experimental group compared to control group (Graph 1, Graph 2, Graph 3 and Graph 4).

Table 1. Demographic Characteristics of Stroke Patients $(\mathrm{N}=48)$

\begin{tabular}{|c|c|c|}
\hline Characteristics & $\begin{array}{c}\text { Control Group } \\
(\mathbf{N}=\mathbf{2 5})\end{array}$ & $\begin{array}{c}\text { Experimental } \\
\text { Group (N=23) }\end{array}$ \\
\hline Age $(\mathrm{M}+\mathrm{SD})$ & $53 \pm 7$ & $55 \pm 10$ \\
\hline Sex & & \\
\hline Male: Female & $15: 10$ & $14: 9$ \\
\hline
\end{tabular}

Table 2. Baseline Characteristics of the Stroke Patients

\begin{tabular}{|c|c|c|}
\hline & $\begin{array}{c}\text { Control Group } \\
\text { (N=25) }\end{array}$ & $\begin{array}{c}\text { Experimental } \\
\text { Group (N=23) }\end{array}$ \\
\hline $\begin{array}{c}\text { Brunnstorm upper limb } \\
\text { recovery stage }\end{array}$ & $\geq 2$ & $\geq 2$ \\
\hline $\begin{array}{c}\text { Modified Rankin Scale } \\
\text { (Mean+SD) }\end{array}$ & $4.64 \pm 0.49$ & $4.22 \pm 0.42$ \\
\hline $\begin{array}{c}\text { Barthel Functional Index } \\
\text { (Mean+SD) }\end{array}$ & $9.60 \pm 7.62$ & $26.96 \pm 18.99$ \\
\hline $\begin{array}{c}\text { Fugl-Meyer Assessment } \\
- \text { Upper Extremity } \\
\text { (Motor) (Mean+SD) }\end{array}$ & $5.28 \pm 2.99$ & $8.17 \pm 5.63$ \\
\hline $\begin{array}{c}\text { Fugl-Meyer Assessment } \\
\text { - Lower Extremity } \\
\text { (Motor) (Mean+SD) }\end{array}$ & $6.04 \pm 3.37$ & $7.83 \pm 4.86$ \\
\hline \multicolumn{2}{|c|}{ (Motor } & \\
\hline
\end{tabular}

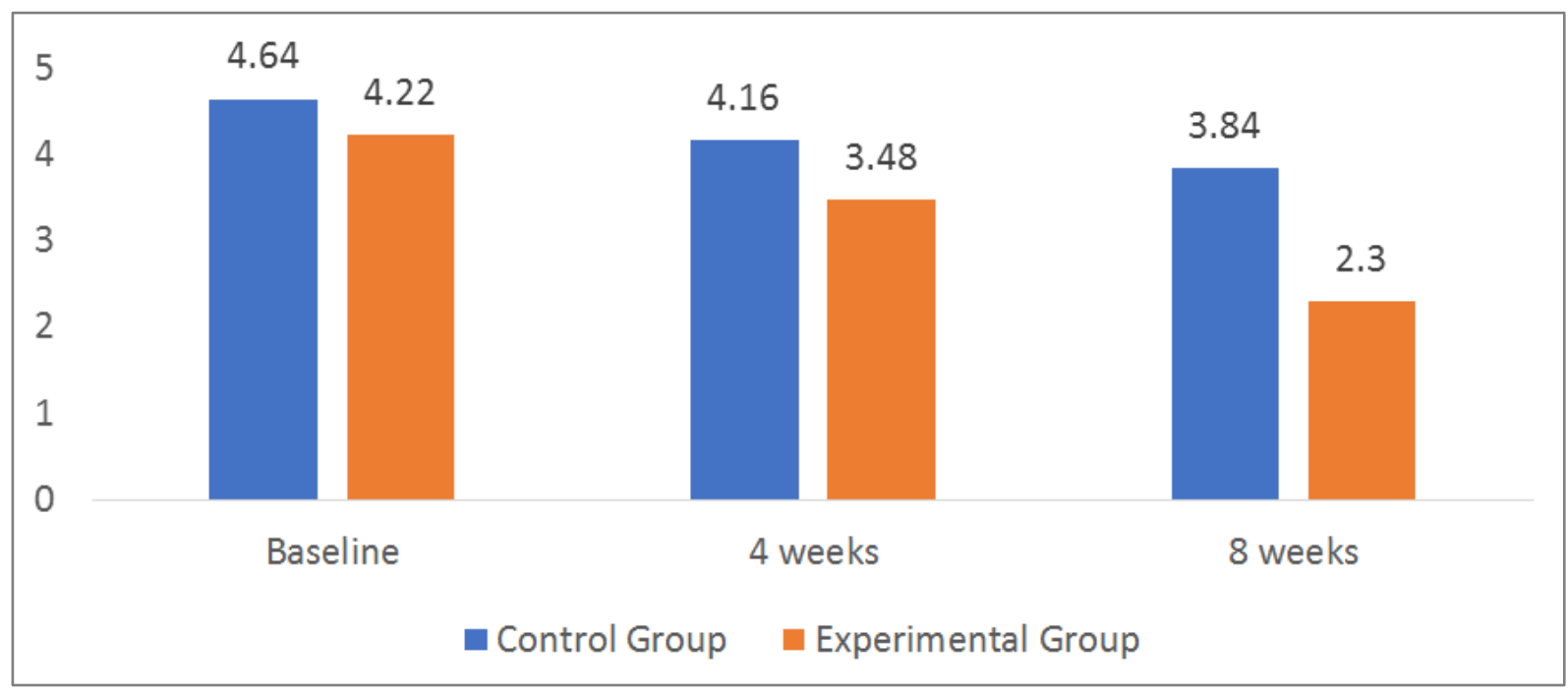

* There is no significant difference between the groups at baseline

Graph 1. Disability status of the patients in both groups (Modified Rankin Scale Score) 


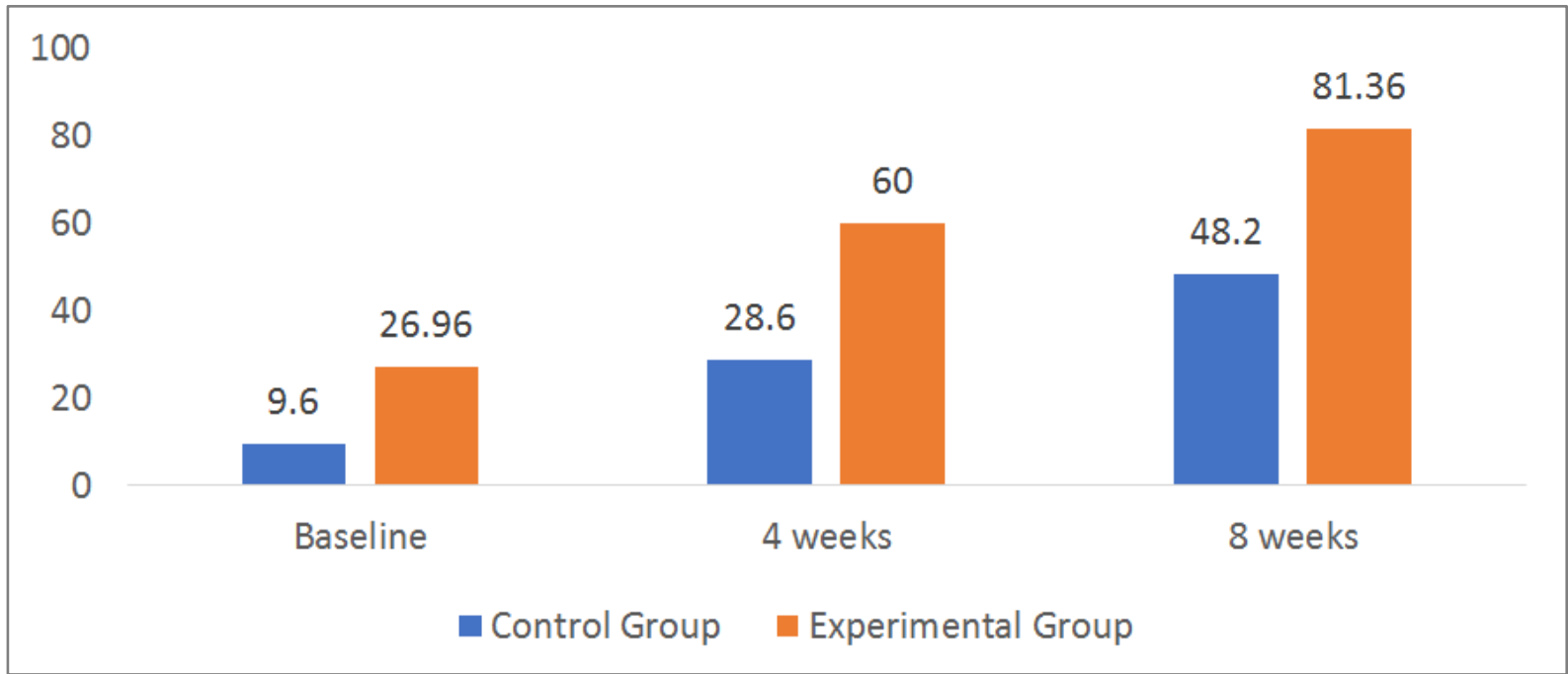

* There is no significant difference between the groups at baseline

\# Non - parametric test was used since the data does not follow normal distribution

Graph 2. Functional Independence of the Patients in both groups (Barthel Functional Index Score)

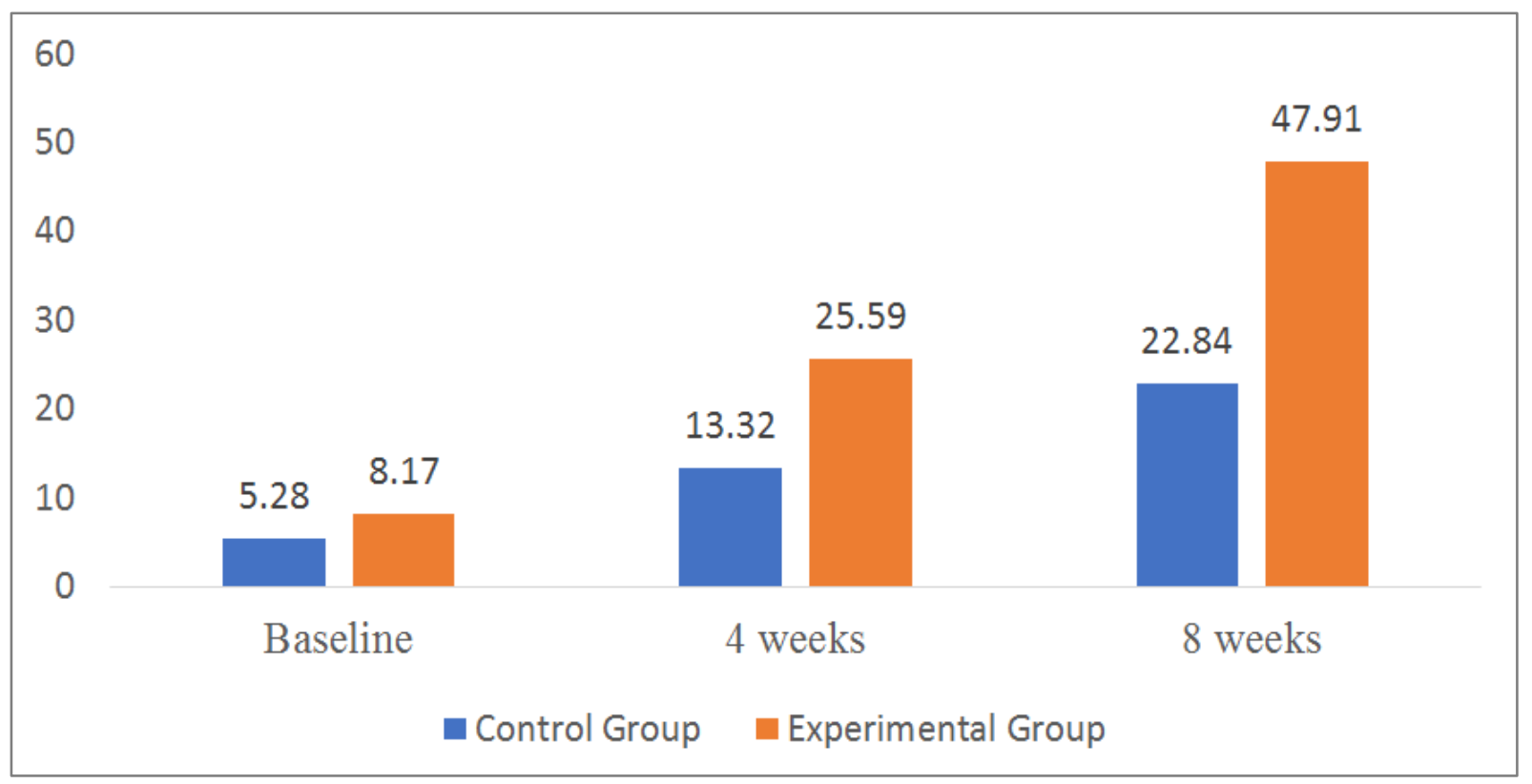

* There is no significant difference between the groups at baseline

\# Non - parametric test was used since the data does not follow normal distribution

Graph 3. Upper Extremity Motor Functions of the patients in both groups (Fugl Meyer Assessment Scale - Upper Extremity) 


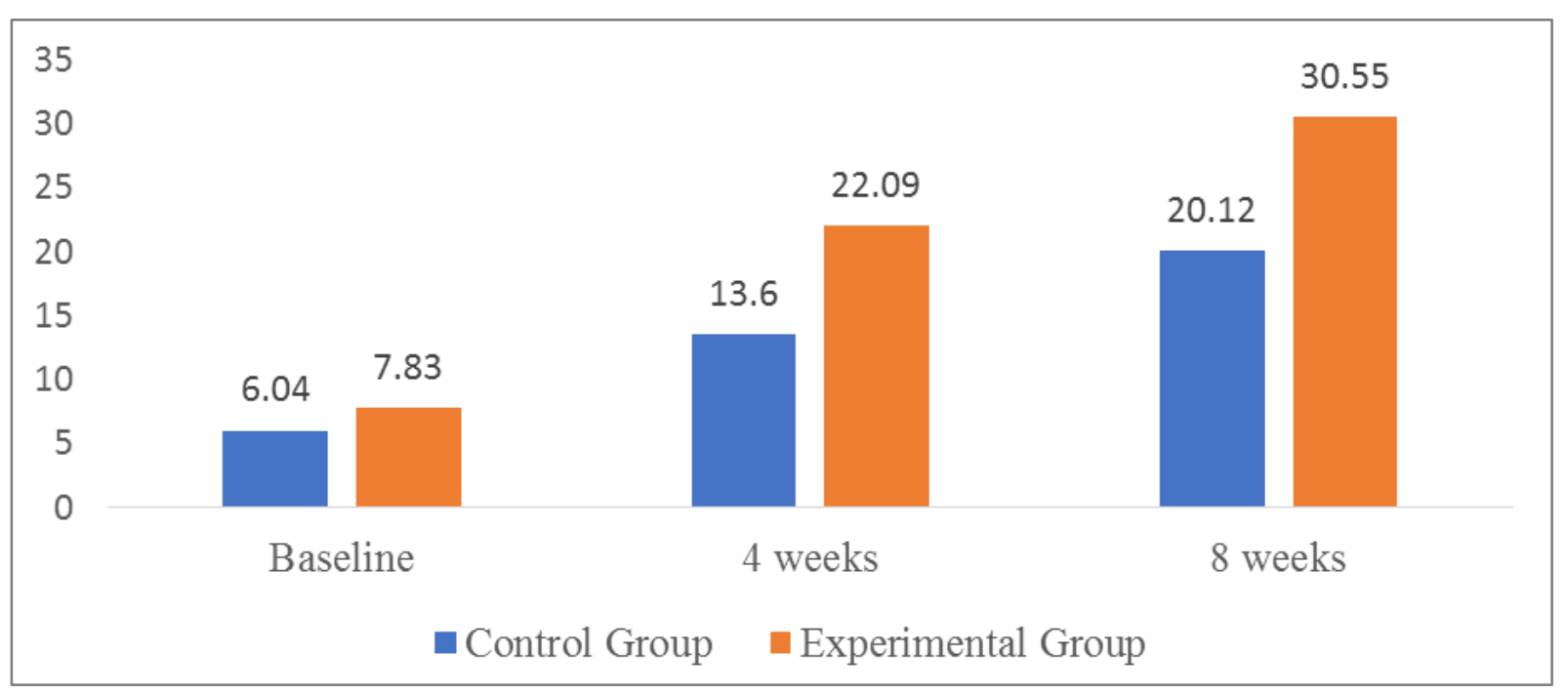

* There is no significant difference between the groups at baseline

Graph 4. Lower Extremity Motor Functions of the patients in both groups (Fugl Meyer Assessment Scale - Lower Extremity)

\section{Discussion}

In this study, 48 stroke patients (25 - Control group, 23 Experimental group) underwent 8 weeks of rehabilitation and their outcomes in terms of disability status, functional independence and motor functions of upper extremity and lower extremity were assessed after 4 weeks and 8 weeks of intervention.

The results of the study showed that there is significant improvement in disability status, functional independence, motor functions of the upper extremity and lower extremity in both groups over the period of 8 weeks $(\mathrm{P}<0.05)$. Between group analysis also showed that there is significant improvement in above parameters in experimental group compared to control group $(\mathrm{P}<0.05)$. There was clinically significant improvement in both groups.

\subsection{Disability of the Stroke Patients}

There is significant improvement in the disability status of the patients with respect to modified Rankin scale in both groups $(\mathrm{P}<0.05)$. The recovery in stroke patients during the early period may be attributed to resolution of oedema and restoration of blood supply to ischemia penumbra [3]. Improvement during the subacute stage could be due to dendritic sprouting, synaptogenesis, restoration of axonal transport, unmasking of the alternate pathways facilitated by structured rehabilitation program [3]. The result of our study supports the findings of Lai (2001) [27] and Rangaraju (2017) [26] on the quality of life of stroke patients.

\subsection{Functional Independence of the Patients}

Functional independence of the patients was improved significantly in both groups $(\mathrm{P}<0.05)$. Improvement may be attributed to redevelopment of cortical inhibition, resolution of diaschisis, alteration in neurotransmitters and bilaterality of brain functions facilitated by functional training. The result of the study supports the study of Musa on functional independence [28]. The improvement in our experimental group is too supported by study findings of Lee [18] on functional independence using Barthel Index. In contrast to the study of Remsik, we found significant improvement on functional independence as it is showed in Barthel index [19].

\subsection{Upper Extremity Motor Functions of the Stroke Patients}

Upper extremity motor functions showed significant improvement in both groups over the period of 8 weeks. Between group analysis revealed significant improvement in experimental group compared to control group $(\mathrm{P}<0.05)$. This may be due to tongue stimulation causing reorganization of the areas of the brain representing the tongue and hand, as tongue being represented bilaterally in brain and tongue stimulation might also cause increase in interhemispheric functional connectivity between homologous regions of the primary sensorimotor cortex, which is also one of the reasons for improvement in upper limb functions after stroke $[19,20,21,22,23,24]$. Periglossal electrical stimulation along with upper limb retraining influences the areas in the brain responsible for motor control of the tongue and the upper limbs to reorganize and remap intra-cortical pathways, establishing a new sensorimotor pathway for the paralyzed upper limb [29]. This is in accordance with the study done by Young (2014), where increase in interhemispheric functional connectivity has been shown to correlate with improvement in Fugl-Meyer Score (motor recovery) in 
stroke patients [20]. Minimum clinically important difference of Fugl Meyer Scale in subacute stroke patients is around 9 for upper extremity motor recovery [30].

\subsection{Lower Extremity Motor Functions of the Stroke Patients}

With respect to lower extremity motor functions of the stroke patients, there was significant improvement in motor functions in experimental group compared to control group $(\mathrm{P}<0.05)$. Our study supports the findings of Cacho (2006) on the effects of rehabilitation on motor functions of lower extremity [31].

\subsection{Tongue Stimulation in Stroke Rehabilitation}

The improvement in motor functions in the experimental group could also be explained with respect to Hebbian theory of neuroplasticity. Based on Hebbian theory, the cells that fire together will wire together. Hebb also suggested that when one cell repeatedly assists in the firing of another cell, the axons of the first cell form synaptic knobs with the soma of the second cell. In case of damage to area controlling the movements, mirror neurons are activated. When a person does a particular action, he will see, hear and feel the performing of the action. These re-afferent sensory neurons will trigger activity in neurons responding to sight, sound and feel of the action [32]. Hebbian learning predicts that the synapses connecting neurons responding to the sound, sight, and feel of a movement and those of the neurons triggering the movement should be activated [33].

Reinforcement of motor behaviour is one of the key mechanisms responsible for training and use of therapy involving tongue stimulation. As the patients were given tongue stimulation and simultaneously made to do assisted or passive movements of the hand and upper limbs, there is visual, auditory cue given to the patients. Another probable mechanism is the simple Pavlovian mechanism, where learning a new behaviour in association with another stimulus and reinforcement leads to the development of new associations and pathways.

\section{Conclusion}

Tongue stimulation along with upper limb retraining has proved to be more beneficial in improving upper limb functions in stroke patients. This is one of the cost effective and easy to administer therapeutic procedures, which can be used for stroke rehabilitation.

\section{Limitations and Recommendations}

The study is limited to small sample size. Many parameters which could have influenced the outcome of the studies are not controlled which includes but not limited to size of the infarct, area of the infarct and comorbidities. Further studies can be done on a larger sample size to find out the effect of tongue stimulation on upper limb functions in various types of stroke patients.

\section{Funding}

There is no funding received for conducting this study.

\section{REFERENCES}

[1] S. K. Kamalakannan, A. S. Gudlavalleti, V. S. Gudlavalleti, S. Goenka and H. Kuper, "Incidence \& prevalence of stroke in India: A systematic review," Indian journal of Medical Research, 146 (2), pp. 175- 185, 2017. DOI: 10.4103/ijmr.IJMR 516 15

[2] K. B. Lee, S. H. Lim, K. H. Kim, K. J. Kim, Y. R. Kim, W. N. Chang, J. W. Yeom, Y. D. Kim, B. Y. Hwang, "Six-month functional recovery of stroke patients: a multi-time-point study," International Journal of Rehabilitation Research, vol. 38, pp. 173-180, 2015. doi: 10.1097/MRR.0000000000000108

[3] K.P.S. Nair, A. B. Taly, "Stroke Rehabilitation: Traditional and Modern Approaches," Neurology India, vol. 50 (1), pp. S85-S93, 2002. Code Number: ni02168

[4] J. K. Harrision, K. S. McArthur, T. J. Quinn, "Assessment scales in stroke: clinimetric and clinical considerations," Clinical Interventions in Aging 2013:8 201-211. http://dx.doi.org/10.2147/CIA.S32405

[5] K. J. Sullivan, J. K. Tilson, S. Y. Cen, D. K. Rose, J. Hershberg, A. Correa, J. Gallichio, M. McLeod, C. Moore, S. S. Wu, P. W. Duncan, "Fugl Meyer Assessment of Sensorimotor Function After Stroke Standardized Training Procedure for Clinical Practice and Clinical Trials," Stroke, vol. 42, pp. 427-432, 2011. https://doi.org/10.1161/STRO KEAHA.110.592766

[6] J. P. Broderick, O. Adeoye and J. Elm, "Evolution of the Modified Rankin Scale and Its Use in Future Stroke Trials," Stroke, vol. 48, 2017. DOI: 10.1161/STROKEAHA.117.0 17866 .

[7] J. L. Banks, C. A. Marotta, "Outcomes Validity and Reliability of the Modified Rankin Scale: Implications for Stroke Clinical Trials. A Literature Review and Synthesis," Stroke, vol 38 (3), pp. 1091-1096, 2007. https://doi.org/10.1161/01.STR.0000258355.23810.c6

[8] T. J. Quinn, P. Langhorne, D. J. Stott, "Barthel Index for Stroke Trials Development, Properties, and Application," Stroke, vol. 42, pp. 1146-1151, 2011. doi: 10.1161/STROKEAHA.110.598540

[9] A. Pollock, S. E. Farmer, M. C. Brady, P. Langhorne, G.E. Mead, J. Mehrholz, F. V. Wijck, "Interventions for improving upper limb function after stroke. Cochrane Database of Systematic Reviews," vol 11, CD010820, 2014. DOI: 10.1002/14651858.CD010820.pub2

[10] M. Gentilucci and R.D. Volta, "Spoken language and arm 
gestures are controlled by the same motor control system," Quarterly Journal of Experimental Psychology, vol 61 (6), pp. 944-57, 2008. doi: 10.1080/17470210701625683.

[11] L. Vainio, K. Tiippana, M. Tiainen, A. Rantala, M. Vainio, "Reaching and grasping with the tongue: Shared motor planning between hand actions and articulatory gestures," Quarterly Journal of Experimental Psychology, vol. Jan, pp. 1-13, 2018. doi.org/10.1177/1747021817738732

[12] M. Tiainen, J. Lukavsky, K. Tiippana, M. Vainio, J. Simko, F. Felisberti, L. Vainio, "Connections of Grasping and Horizontal Hand Movements with Articulation in Czech Speakers," Frontiers in Psychology, vol.8, pp. 516, 2017. https://doi.org/10.3389/fpsyg.2017.00516.

[13] G. Leonard, Y. Lapierre, J. K. Chen, R. Wardini, J. Crane, A. Ptito, "Noninvasive tongue stimulation combined with intensive cognitive and physical rehabilitation induces neuroplastic changes in patients with multiple sclerosis; A multimodal neuroimaging study," Multiple Sclerosis Journal - Experimental, Translational and Clinical, vol 3(1), 2017. doi: $10.1177 / 2055217317690561$.

[14] E. M. Gradin Frabon, E. S. Petrini, V. M. Cardoso, J. C. Batista, S. M. Motonaga, V. C. Marino, "Immediate effects of tongue trills associated with transcutaneous electrical nerve stimulation," Codas, vol 29 (3), 2017. DOI: $10.1590 / 2317-1782 / 20172015311$.

[15] A. Barikroo, G. Berretin-Felix, G. Carnaby, M. Crary, "Effect of transcutaneous electrical stimulation amplitude on timing of swallow pressure peaks between healthy young and older adults," Gerodontology, vol. 34 (1), pp. 24-32, 2017. doi: 10.1111/ger.12221. Epub 2015 Dec 23

[16] J. C. Wildenberg, M. E. Tyler, Y. P. Danilov, K. A. Kaczmarek, M. E. Meyerand, "High-resolution fMRI detects neuromodulation of individual brainstem nuclei by electrical tongue stimulation in balance impaired individuals," Neuroimage, vol. 56(4), pp. 2129-2137, 2011. DOI: 10.1016/j.neuroimage.2011.03.074

[17] J. Jayavelu, J. Sethi, S. Kohli, T. Matin, "Effect of Electrical Stimulation of Tongue in Rehabilitation - A Systematic Review," Universal Journal of Public Health, Vol. 9, No. 5, pp. 253 - 262, 2021. DOI: 10.13189/ujph.2021.090507

[18] S. Hiragami, Y. Inoue, K. Harada, "Minimal clinically important difference for the Fugl-Meyer assessment of the upper extremity in convalescent stroke patients with moderate to severe hemiparesis," The Journal of Physical Therapy Science, vol. 31, pp. 917-921, 2019. DOI: 10.1589/jpts.31.917

[19] S. Rangaraju, D. Haussen, R. G. Nogueira, R. Nahab, M. Frankel, "Comparison of 3-Month Stroke Disability and Quality of Life across Modified Rankin Scale Categories," Interventional Neurology, vol. 6(1-2), pp. 36- 41, 2017. doi: 10.1159/000452634. Epub 2016 Nov 16.

[20] S. M. Lai, P. W. Duncan, "Stroke Recovery Profile and the Modified Rankin Assessment," Neuroepidemiology, vol. 20 (1), pp. 26-30, 2001. doi: 10.1159/000054754.

[21] K. I. Musa, T. J. Keegan, "The change of Barthel Index scores from the time of discharge until 3-month post discharge among acute stroke patients in Malaysia: A random intercept model," PLoS ONE 13(12): e0208594, 2018. DOI: 10.1371/journal.pone.0208594

[22] S. Lee, S. S. Kim, B. H. Lee, "Action observation training and brain-computer interface controlled functional electrical stimulation enhance upper extremity performance and cortical activation in patients with stroke: a randomized controlled trial," Physiother Theory Practice, vol. 7, pp. 1-9, 2020. doi: 10.1080/09593985.2020.1831114

[23] A. B. Remsik, L. Williams, K. Gjini, K. Dodd, J. Thoma, T. Jacobson, M. Walczak, M. McMillan, S. Rajan, B. M. Young, Z. Nigogosyan, H. Advani, R. Mohanty, N. Tellapragada, J. Allen, M. Mazrooyisedbdani. L. M. Walton, P. L. E Van Kan, T. J. Kang, J. A. Sattn, V. A. Nair, D. F. Edwards, J. C. Williams, V. Prabhakaran, "Ipsilesional $\mathrm{Mu}$ Rhythm Desynchronization and Changes in Motor Behavior Following Post Stroke BCI Intervention for Motor Rehabilitation," Frontiers in Neuroscience, vol. 13, article 53, 2019. DOI: 10.3389/fnins. 2019.00053

[24] B. M. Young, Z. Nigogosyan, A. Remsik, L. M. Walton, J. Song, V. A. Nair, "Changes in functional connectivity correlate with behavioral gains in stroke patients after therapy using a brain-computer interface device," Frontiers in Neuroengineering, vol. 7, pp. 25, 2014. doi: 10.3389/fneng.2014.00025. eCollection 2014.

[25] B. M. Young, J. M. Stamm, J. Song, A. B. Remsik, V. A. Nair, M. E. Tyler, D. F. Edwards, K. Caldera, J. A. Sattin, J. C. Williams, V. Prabhakaran, "Brain-Computer Interface Training after Stroke Affects Patterns of Brain-Behavior Relationships in Corticospinal Motor Fibers," Frontiers in Human Neuroscience, vol. 10, pp. 457, 2016. doi: 10.3389/fnhum.2016.00457. PMCID: PMC5025476.

[26] R. Mohanty, A. M. Sinha, A. B. Remsik, K. C. Dodd, B. M. Young, T. Jacobson, M. McMillan, J. Thoma, H. Advani, V. A. Nair, T. J. Kang, K. Caldera, D. F. Edwards, J. C. Williams, V. Prabhakaran, "Machine Learning Classification to Identify the Stage of Brain-Computer Interface Therapy for Stroke Rehabilitation Using Functional Connectivity," Frontiers in Neuroscience, vol. 12, pp.353, 2018. doi: 10.3389/fnins.2018.00353.

[27] A. Remsik, B. M. Young, R. Vermilyea, L. Kiekoefer, J. Abrams, S. E. Elmore, P. Schultz, V. Nair, D. Edwards, J. Williams, V. Prabhakaran, "A review of the progression and future implications of brain-computer interface therapies for restoration of distal upper extremity motor function after stroke," Expert Review of Medical Devices, vol. 13 (5), pp. 445-454, 2016. doi: $10.1080 / 17434440.2016 .1174572$.

[28] A. Ramos-Murguialday, D. Broetz, M. Rea, L. Laer, O. Yilmaz, F. L. Brasil, G. Liberati, M. R. Curado, E. Garcio-Cossio, A. Vyziotis, W. Cho, M. Agostini, E. Soares, S. Soekadar, A. Carea, L. G. Cohen, N. Birbaumer, "Brain-Machine-Interface in Chronic Stroke Rehabilitation: A Controlled Study," Annals of Neurology, vol. 74 (1), pp. 100-108, 2013. DOI: 10.1002/ana.23879.

[29] M. Ghovanloo and A. Butler, "Complete Project: Accelerating Upper Limb Rehabilitation in Stroke Patients by Engaging Synchronous Tongue and Wrist Motion," Co-PIs. Georgia Institute of Technology, 2Georgia State University, 3VA Medical Center.

[30] K N Arya, R. Verma and R. K. Garg, "Estimating the Minimal Clinically Important Difference of an Upper Extremity Recovery Measure in Subacute Stroke Patients," Top Stroke Rehabilitation, vol. Top Stroke Rehabil, Vol.18, pp. 599-610, 2011. doi: 10.1310/tsr18s01-599.

[31] R. Cacho, E. Cacho, "POST-stroke motor and functional 
evaluations: A clinical correlation using Fugl-Meyer assessment scale, Berg balance scale and Barthel index," Arq Neuropsiquiatr, vol. 64 (3-B), pp. 731-735, 2006. DOI: 10.1590/S0004-282X2006000500006

[32] C. Keysers, D. Perett, "Demystifying social cognition: a Hebbian perspective," Trends Cogn Sci, vol.11, pp. 501-507, 2004. doi: 10.1016/j.tics.2004.09.005.
[33] C. Keysers, V. Gazzola, "Hebbian learning and predictive mirror neurons for actions, sensations and emotions," Phil. Trans. R. Soc. B 369: 20130175, 2014. http://dx.doi.org/10.1098/rstb.2013.0175. 